\title{
APPLICATION OF LIQUID CHROMATOGRAPHY COUPLED WITH MASS SPECTROMETRY IN THE IMPURITY PROFILING OF DRUG SUBSTANCES AND PRODUCTS
}

\author{
AKSHATHA HS, GURUPADAYYA BM* \\ Department of Pharmaceutical Chemistry, JSS College of Pharmacy, Jagadguru Sri Shivarathreeshwara University, Sri Shivarathreeshwara \\ Nagar, Mysore, Karnataka, India. Email: bmgurupadayya@jssuni.edu.in \\ Received: 16 December 2017, Revised and Accepted: 24 January 2018
}

\begin{abstract}
As the drug safety and efficacy is hampered in the presence of an impurity, the international regulatory agencies laid down stringent limits for the control of impurities in the active pharmaceutical ingredient and pharmaceutical formulations. The conventional approaches lack the characterization of impurities in trace levels, due to sensitivity issues, hyphenated techniques are preferred. Among the modern hyphenated techniques, liquid chromatography-mass spectrometry (LC-MS) has high sensitivity and can analyze large number of organic compounds in a short period of time. In the present study, the impurity profiling of various drug substances and products using LC-MS about past 6 years were retrospect for its importance, instrumentations, and applications.
\end{abstract}

Keywords: Impurities, International regulatory agencies, Hyphenated techniques, Liquid chromatography-mass spectrometry.

(C) 2018 The Authors. Published by Innovare Academic Sciences Pvt Ltd. This is an open access article under the CC BY license (http://creativecommons. org/licenses/by/4. 0/) DOI: http://dx.doi.org/10.22159/ajpcr.2018.v11i5.24212.

\section{INTRODUCTION}

ICH Guidelines defines the impurity as "Any component of the medicinal product which is not the chemical entity defined as the active substance or excipients in the product" [1]. The impurity profile is the characterization of the identified and unidentified impurities that are present in the drug product [2].

The critical part of drug discovery and development is to establish a qualitative and quantitative impurity profile of pharmaceuticals. The quality of the pharmaceutical product is affected by impurities. Drug regulatory authorities expect to furnish in detail all impurities that might merge during the production and storage, which provides the basis for a comprehensive risk assessment.

The impurity profile can provide complete information about the manufacturing process, degradation process and it is diagnostic for the overall quality of the final product. The drug safety and quality can be ensured by knowing the identity of the impurities, thereby helps to analyze the abnormality in the production.

The impurities in pharmaceutical products are not only restricted to the process residual impurities, manufacturing impurities, and degradation products resulting from storage but also includes genotoxic impurities. Genotoxic impurities induce the genetic metamorphosis, chromosomal ruptures or chromosomal disruptions and it may cause cancer in humans.

If impurity profiling is not addressed properly, then the regulatory bodies may compel to recall the finished drug products or reject the approval of such products, or the drug may be kept on hold. In past few years the US-FDA ordered for the recall of few finished pharmaceutical products such as adagen (Pegademase bovine) injection, azelastine hydrochloride ophthalmic solution, brimonidine tartrate ophthalmic solution, budeprion XL (Bupropion $\mathrm{HCl}$ ER Tablets), prednisolone sodium phosphate oral solution, and topiramate 25 and $200 \mathrm{mg}$ tablets due to the presence of impurities and degradation products [3].

The present review article endures the works of impurity profiling of various drug substances and product by employing the liquid chromatography-mass spectrometry (LC-MS) technique. The article mainly highlights the regulatory requirements for the control of impurities, columns, interface, ionization techniques, and mass analyzer used in the past 6 years of works on impurity profiling. Fig. 1 represents the number of research works that are undergone in the field of impurity profiling using LC-MS in past 6 years.

\section{NEED FOR THE IMPURITY PROFILING OF PHARMACEUTICAL PRODUCTS}

Benzopyridooxathiazepine derivatives are potent, antimitotic class of cytotoxic compounds. The in vitro cytotoxicity studies showed promising results. However, the in vivo activity was poor due to drug decomposition and the advent of possible adverse effect showed due to the formation of degradation products. The study showed that 10 main degradation products out of which seven structures were elucidated. The structural comparison showed that the stability problem arises due to oxathiazepine ring of BZN which could have some consequences on storage conditions [4].

MLN9708 is a small molecule proteasome which is currently under investigation developed by Millennium: The Takeda Oncology Company, on the evaluation of impurities, found that 2, 5-dichlorobenzoyl chloride (DCBC) was predicted to be mutagenic. The carryover of this impurity into drug substance was low due to multiple acid; base workup steps. However, FDA suggests to provide the verification data [5]

\section{TYPES AND SOURCES OF IMPURITIES}

As per the ICH guidelines, the impurity in pharmaceutical entities and products can be categorized into five subheadings:

- Organic impurities

- Inorganic impurities

- Residual solvents

- Elemental impurities

- Genotoxic impurities.

Organic impurities emerge during the course of production and/ or while storing new drug substance. Organic impurities are further classified as: 
- Starting materials

- By-products

- Intermediates

- Degradation products

- Reagents, ligands, and catalyst.

Inorganic impurities arise during the manufacturing stage, and they can be classified as:

- Reagents, ligands, and catalyst

- Heavy metals or other residual metals

- Inorganic salts

- Other materials (Ex: Charcoal and filter aids) [1].

Residual solvents are the remnants of the solvents used in the production of pharmaceutical entities, excipients or in the process of formulating the drug product. Residual solvents can be classified based on their toxicity levels as:

- Class I solvents: The use of solvents present in this class must be avoided. Ex: Benzene and carbon tetrachloride.

- Class II solvents: The use of solvents present in this class must be controlled. Ex: Acetonitrile, chloroform, and Hexane.

- Class III solvents: The solvents present in this class have low lethal effects. Ex: Acetic acid, acetone, and formic acid.

- Class IV solvents: The solvents present in this class lack in required toxicological data. Ex: Isopropyl ether, petroleum ether, and trifluoroacetic acid [6].

ICH Q3B(R2) guidelines for impurities in new drug product includes the impurities that arise due to deterioration of pharmaceutical entities or the products arise due to the reaction between drug substance and excipients and/or immediate packaging materials [7].

Elemental impurities in pharmaceuticals emerge from various sources, i.e., maybe the unconsumed catalyst that was added purposefully in the process of production or may be formed due to the reaction between the manufacturing equipment or packaging systems or exist in the drug product.

Elemental impurities may be classified as:

- Class I elements: The elements of this class have minimal or no use in the manufacture of medicinal products. However, if present they have lethal effects on human beings. Ex: $\mathrm{As}, \mathrm{Cd}, \mathrm{Pb}$, and $\mathrm{Hg}$.

- Class II elements: The elements of this class have route dependent toxicity.

- Class 2A: The elements of this class have a relatively high risk of existence in the medicinal product. Ex: $\mathrm{Co}, \mathrm{V}$, and $\mathrm{Ni}$.

- Class 2B: The elements of this class have a low possibility of a presence in the medicinal product. $\mathrm{Ex}: \mathrm{Ag}, \mathrm{Rh}, \mathrm{Au}, \mathrm{Ru}$, and $\mathrm{Pd}$.

- Class III elements: The elements of this class have comparatively low lethality by enteral route of administration, but may be toxic in case of inhalation and parenteral route.

- Other elements: The elements of this class have low elementary toxicity and/or difference in provincial regulations [8].

Genotoxic impurities are DNA reactive substances can injure DNA, when present at low levels leading to the transformation of DNA, and therefore, likely cause cancer [9]. They can be classified into two types,

- Mutagenic carcinogens: These are usually found by bacterial reverse mutation (mutagenicity) assay. Ex: DCBC is a mutagenic impurity present in MLN9708 proteasomes [5].

- Non-mutagenic genotoxicants: These have threshold mechanism, and at low levels, they do not pose a carcinogenic risk in humans. Ex: 2-bromo-2-chloro-1,1-difluoroethylene is a genotoxic degradation product of Halothane [10].

\section{REGULATORY REQUIREMENTS}

The main objective of the regulatory bodies is to establish the safety, efficacy, and quality of drug products. Presence of impurities in the pharmaceutical entities and product may lead to undesirable pharmacological and toxicological effects, which in turn effect the safety and efficacy of the drug.

Therefore, various regulatory agencies have enforced reporting, identification, qualification, and quantification impurity thresholds for assessing the safety of pharmaceutical substances and their associated dosage forms. Table 1 provides various guidelines lay down by the various regulatory agencies.

\section{QUALIFICATION OF IMPURITIES}

Qualification is the process of obtaining and assessing data that provides the biological safety of a particular impurity or given impurity profile at the level(s) described. Table 2 provides the threshold levels for reporting, identification, and qualification of impurities [1].

\section{CONVENTIONAL APPROACHES FOR THE ISOLATION AND CHARACTERIZATION OF IMPURITIES}

Before two and half decades, there were no precise methods to isolate and characterize the impurities. The characterization of impurities was based on the quantification of active ingredient content by nonspecific titrimetric [23] and photometric methods (such as UV spectroscopy [24], IR, Raman spectroscopy [25], and nuclear magnetic resonance [NMR] [26]), which were supported by the physical constants and some limit tests for known impurities. Even the pharmacopeias were suggesting various nonspecific characterization methods for determining the content of active ingredients. Due to the emergence of chromatography in mid-19 $9^{\text {th }}$ century, various chromatographic methods such as capillary electrophoresis (CE) [27], Chiral separations [28], gas chromatography (GC) [29], high-pressure liquid chromatography (HPLC) [30], supercritical fluid chromatography [31], and Thin-layer chromatography (TLC) [32] were employed for the separation of various impurities in drug substance and products. Followed by the isolation/enrichment/synthesis by solid phase extraction, liquidliquid extraction, accelerated solvent extraction, supercritical fluid extraction, column chromatography, flash chromatography, TLC, etc., and later spectrophotometric characterization of impurities using UV spectroscopy, IR, Raman spectroscopy, and NMR.

\section{STRUCTURAL CHARACTERIZATION USING MODERN HYPHENATED TECHNIQUES}

As the process of impurity profiling takes more time for the identification, separation, characterization and quantification using conventional methods, researchers prefer to use one equipment for all the purpose. This can be achieved by employing the modern hyphenated techniques that possess both the separation and characterization of impurities in single equipment. The commonly used modern hyphenated techniques for the isolation and characterization are as follows GC-MS [33], LC-MS [34], LC-MS-MS [35], LC-inductively coupled plasma (ICP)-MS [36], CE-ICP-MS [37], etc.

\section{HISTORY OF LC-MS}

The mass spectrometer is considered as a better detector for LC applications as LC requires sensitivity, specificity, and versatility to provide both qualitative and quantitative analysis of a wide variety of compounds. Mass spectrometer was discovered by Francis Aston in early 1920s based on Thomson's discovery of the electron. Victor Tal'roze was pioneer in attempting to couple LC with MS in 1960s by directly spraying liquid into the ionization chamber of low-pressure electron impact mass spectrometer. In the same year, Malcom Dole demonstrated electron spray ionization. In early 1970s Tal'roze provided three strategies to address the interface issue, they are atmospheric pressure chemical ionization, moving wire system, which led to the moving belt interface and direct liquid introduction [38] Table 3. 


\section{ADVANTAGES OF USING LC-MS OVER OTHER ANALYTICAL TECHNIQUES}

Most of the analytical techniques lack sensitivity and are not able to deduce the structure of the unknown impurities. Hence, LC-MS is considered as an essential and versatile tool for the structural elucidation of impurities. It is handy and efficient since it provides rapid and effective separation. The structures from the unknown impurities can be obtained by characterization on the basis of mass separations from the drug in the form of ions; molecular formulae can be determined from specific mass measurements [39]. As the instrument has high sensitivity, it can detect impurities in trace levels up to fematogram $(1 \mathrm{fg}=10-15 \mathrm{~g})$ level in bulk samples [40]. The structural elucidation with LC-MS can help in the determination of route cause for arise of impurities and thereby helps in controlling the impurity levels in the drug substance or product.

\section{INSTRUMENTATION OF LC-MS}

LC-MS instrumentation can be classified into two parts, i.e., HPLC system and mass spectrometry [41]. The LC-MS instrumentation is briefly given in Fig. 2 .

\section{HPLC system}

The HPLC system works as follows, the mobile phase is pumped from a reservoir and the sample is injected through injector which enters the column along with mobile phase. The separation occurs in the column, and the separated constituents are detected by the detectors. The most commonly used pumps are piston pumps. The pistons are commonly constructed from beryl glass, called sapphire pistons. The introduction of sample successfully into the columns is achieved using loop injectors and valve injectors [41]

In most of the studies, $0.1 \%$ aqueous formic acid with the organic solvents with or without formic acid was used, as they have various advantages when compared to acetic acid and trifluoroacetate. Formic acid has less molecular weight than acetic acid and trifluoroacetate; hence, they cause less interference in the mass spectrum. For the analysis of basic compounds, acidic mobile phases are needed. The use of low $\mathrm{pH}$ mobile phase keeps residual silanol in an undissociated state. Formic acid has lower contamination levels than acetic acid [42].

Column is considered as the heart of HPLC system. The most commonly used silica column is C18 column or octadodecyl silica column. It is a non-polar organic phase chemically bonded to silica. In few cases, C8 columns are preferred. Table 4 gives the various commercially available C18 and C8 columns which were used in the impurity profiling works carried out from 2012 to 2017.

The detectors in LC-MS system is mass spectrometers. However, other HPLC detectors are either placed in series or a part of mobile phase can be diverted to mass spectrometer by employing splitters. Secondary detectors used may be refractive index detector, conductivity detector, ultraviolet detector or fluorimeters.

Table 1: International guidelines outlining the regulatory requirements for the control of impurities in drug substances and drug products

\begin{tabular}{|c|c|c|c|}
\hline Regulatory agency & Guidelines & Issue date & References \\
\hline \multirow[t]{5}{*}{ ICH (USA, Europe and Japan) } & Q3A (R2) Impurities in new drug substances & $25^{\text {th }}$ October 2006 & [1] \\
\hline & Q3B (R2) Impurities in new drug products & $2^{\text {nd }} J$ June 2006 & [7] \\
\hline & Q3C (R6) Impurities guideline for residual solvents & $20^{\text {th }}$ October 2016 & [6] \\
\hline & Q3D Guideline for elemental impurities & $16^{\text {th }}$ December 2014 & [8] \\
\hline & $\begin{array}{l}\text { M7(R1) Assessment and control of DNA } \\
\text { reactive (mutagenic) impurities in pharmaceuticals to limit } \\
\text { potential carcinogenic risk }\end{array}$ & $31^{\text {st }}$ March 2017 & [9] \\
\hline \multirow[t]{5}{*}{ EMA (Europe) } & $\begin{array}{l}\text { EMA/CHMP/CVMP/QWP/450653/2006 Assessment of the } \\
\text { quality of medicinal products containing existing/known } \\
\text { active substances }\end{array}$ & $9^{\text {th }}$ February 2009 & [11] \\
\hline & $\begin{array}{l}\text { CPMP/QWP/1529/04 Control of impurities of } \\
\text { pharmaceutical substances }\end{array}$ & $22^{\text {nd }}$ April 2004 & {$[12]$} \\
\hline & $\begin{array}{l}\text { CPMP/SWP5199/02 and EMEA/CHMP/ } \\
\text { QWP/251344/2006 Guidelines on the limit of genotoxic } \\
\text { impurities }\end{array}$ & $28^{\text {th }}$ June 2006 & [13] \\
\hline & $\begin{array}{l}\text { EMEA/CHMP/SWP/4446/2000 Guideline on the } \\
\text { specification limits for residues of metal catalyst or metal } \\
\text { reagent }\end{array}$ & $21^{\text {st }}$ February 2008 & {$[14]$} \\
\hline & $\begin{array}{l}\text { EMA/CHMP/CVMP/QWP/199250/2009 Guideline on } \\
\text { setting specification for related impurities in antibiotics }\end{array}$ & $30^{\text {th }}$ June 2013 & {$[15]$} \\
\hline \multirow[t]{5}{*}{ US-FDA } & NDAs: Impurities in new drug substances & February 2000 & [16] \\
\hline & ANDAs: Impurities in new drug substances & June 2009 & [17] \\
\hline & ANDAs: Impurities in new drug products & November 2010 & [18] \\
\hline & Elemental impurities in drug products (draft) & June2016 & [19] \\
\hline & $\begin{array}{l}\text { Genotoxic and carcinogenic impurities in drug substances } \\
\text { and products: Recommended approach (draft) }\end{array}$ & December 2008 & [20] \\
\hline Health Canada & Impurities in existing drug substances and products & $6^{\text {th }}$ September 2005 & [21] \\
\hline TGA (Australia) & $\begin{array}{l}\text { Guidance 18: Impurities in drug substances and drug } \\
\text { products }\end{array}$ & $9^{\text {th }}$ August 2013 & [22] \\
\hline
\end{tabular}

Table 2: Reporting, identification and qualification thresholds for the impurities in pharmaceuticals

\begin{tabular}{llll}
\hline Maximum Daily dose & Reporting threshold & Identification threshold & Qualification threshold \\
\hline$\leq 2 \mathrm{~g} / \mathrm{d}$ & $0.05 \%$ & $0.10 \%$ or $1.0 \mathrm{mg} / \mathrm{d}$ & $0.15 \%$ or $1.0 \mathrm{mg} / \mathrm{day}$ intake (whichever \\
& & intake (whichever is maximum) & is maximum) \\
$>2 \mathrm{~g} / \mathrm{d}$ & $0.03 \%$ & $0.05 \%$ & $0.05 \%$ \\
\hline
\end{tabular}




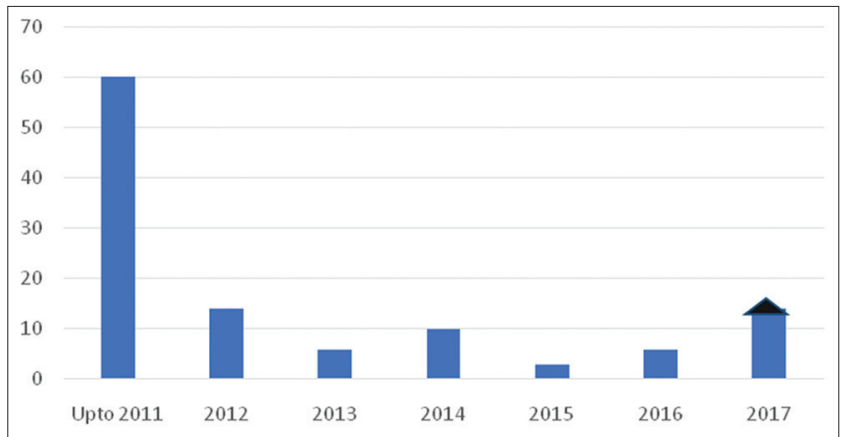

Fig. 1: Articles published on the liquid chromatography-mass spectrometry in the impurity profiling of pharmaceuticals

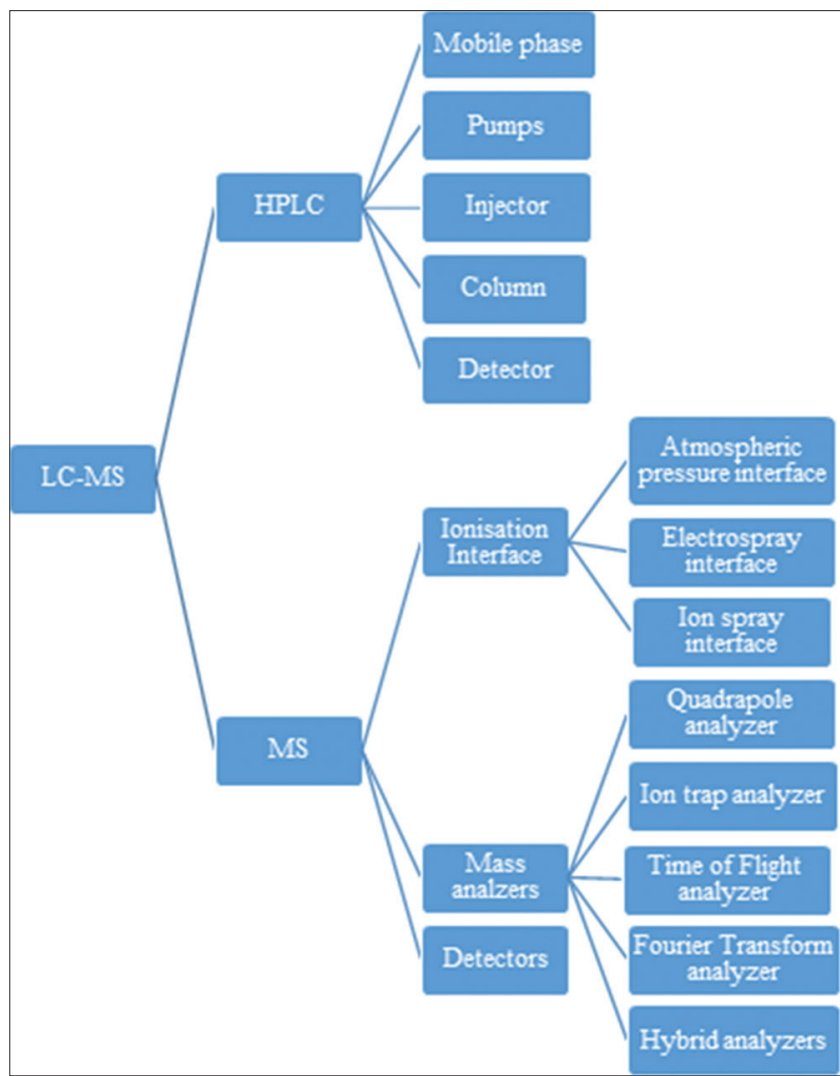

Fig. 2: Instrumentation of liquid chromatography-mass spectrometry

Mass spectrometry

The role of interface in the LC-MS is that it must specifically retain the compound of interest by removing the volatile solvents and additives. As most of the target compounds are uncharged in the HPLC eluent, the interface helps in the ionization of the molecules. Atmospheric pressure interfaces for LC-MS system are of two types, electron spray and ion spray or atmospheric pressure chemical ionization. The commercially built mass spectrometers contain both interfaces which allow the switching of modes based on the area of interest. Positive ionization mode gives rise to molecular ions and solvent adducts, whereas, negative ionization mode gives rise to deprotonated ions. Electron spray interfaces can be mainly used for compounds with high polarity and ionization properties. Ion spray interfaces are recommended when the flow rate from the HPLC system is up to $2 \mathrm{~mL} / \mathrm{min}$, and the effluent polarity is very low [41].

The heart of mass spectrometer is mass analyzer. Quadrupole is less expensive mass analyzer whereas ion trap analyzers are 10 - 100 times more sensitive than quadruple and they require less maintenance. Time
Table 3: List of discoveries in the field of LC-MS

\begin{tabular}{|c|c|}
\hline Year & Discoveries \\
\hline 1907 & Discovery of electron by Thomson \\
\hline 1913 & $\begin{array}{l}\text { First spectrum that demonstrates two different } \\
\text { isotopes of Neon by Thomson }\end{array}$ \\
\hline 1919 & $\begin{array}{l}\text { Development of First mass spectrometer by } \\
\text { Francis Astom }\end{array}$ \\
\hline 1922 & $\begin{array}{l}\text { Use of First electron ionization method by } \\
\text { Smyth }\end{array}$ \\
\hline Late $1960 \mathrm{~s}$ & $\begin{array}{l}\text { First attempt to couple LC with MS by Victor } \\
\text { Tol'roze }\end{array}$ \\
\hline Late $1960 \mathrm{~s}$ & $\begin{array}{l}\text { Demonstration of Electron spray at } \\
\text { atmospheric pressure }\end{array}$ \\
\hline Early 1970 s & $\begin{array}{l}\text { APCI, the moving wire system and direct liquid } \\
\text { introduction were studied by Victor Tol'roze }\end{array}$ \\
\hline 1979 & $\begin{array}{l}\text { Incorporation of direct liquid injection probe } \\
\text { approach into first available LC-MS interfaces } \\
\text { by Hewlett-packard }\end{array}$ \\
\hline $1980 \mathrm{~s}$ & $\begin{array}{l}\text { Commercialization of a moving belt LC-MS } \\
\text { interface by Finnigan }\end{array}$ \\
\hline 1984 & $\begin{array}{l}\text { Development of thermospray LC-MS by Marvin } \\
\text { Vestal }\end{array}$ \\
\hline 1989 & $\begin{array}{l}\text { Commercialization of triple quadrupole LC-MS/ } \\
\text { MS by AB Sciex }\end{array}$ \\
\hline
\end{tabular}

LC-MS: Liquid chromatography-mass spectrometry

of flight mass analyzers can analyze very large biological molecules. Fourier transform analyzers are non-destructive LC-MS detectors as they produce mass spectra using ion cyclotron resonance. But in most of the impurity profiling studies, hybrid mass analyzers were employed. The determination of trace levels of impurities cannot be achieved using single analyzer. Few of the hybrid mass analyzers employed in the studies were as follows Triple Quadrupole, Orbitrap, Q-Trap, Q-IT, Q-TOF, IT-TOF, etc. The commonly used detectors of ions are electron multiplier tube, faraday cup, scintillation counter, etc. [41].

\section{UTILIZATION OF LC-MS IN IMPURITY PROFILING}

\section{Role of LC-MS in process related impurity profiling}

Process-related impurities are potential impurities that emerge during the API manufacturing process which includes the starting material, intermediate material, and by-products, which may be organic or inorganic in nature.

Impurity analysis of bitespiramycin by Ming et al. [40], provided information on 9 major components, 5 minor components, 12 new related substances, and 12 unknown related substances which were partially characterized. Few of the proposed related substances characterized were 4-propionyl SPM I, 4-(iso)butyryl SPM I, 4-(iso) hexadienyl SPM II, etc.

The process of structural elucidation can be simplified by employing various characterization tools. Andras et al. [47] were able to reveal the presence of a novel by-product, 4-phenyl-naphtopyran indapoxetine by utilizing the results obtained from NMR along with the results obtained from LC-MS for the structural elucidation. In the same way, Musty et al. [90] were able to characterize two process-related impurities using NMR results along with LC-MS.

Few drugs of microbial origin such as antibiotics gain impurities during the process of fermentation. Chopra et al. [86] analyzed the impurities in tylosin. The study revealed the presence of 4 major impurities and 23 unknown impurities arised during the process of fermentation. The unknown impurities were easily characterized and quantified using LC-MS technique.

Role of LC-MS in impurity profiling of product-related impurities Product-related impurities emerge during the manufacture and/ or storage due to the molecular variation of the intended product structure and degradation products. In most of the cases, product- 
Table 4: List of columns used in the impurity separation

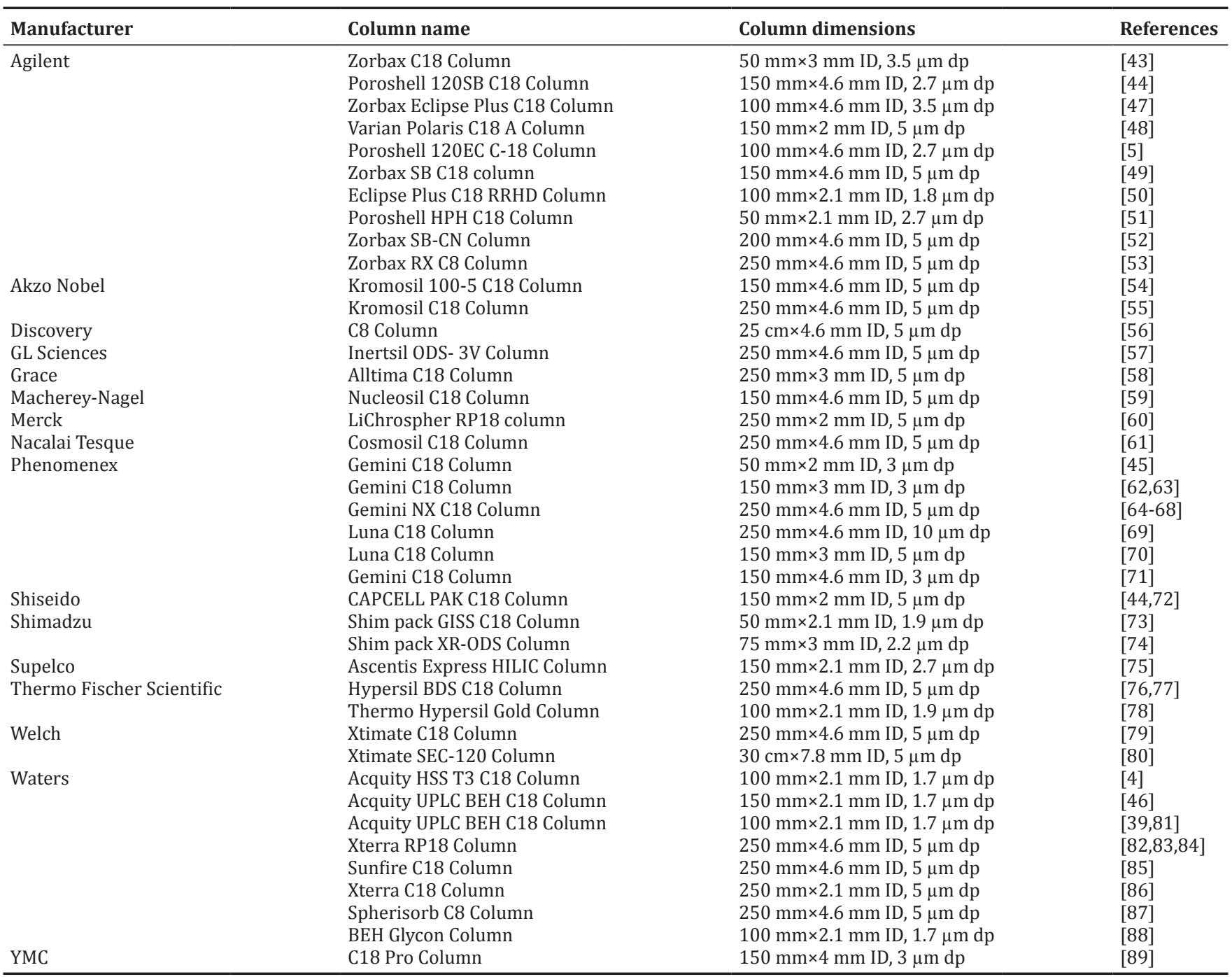

related impurities emerge from the reaction of drug component with excipients such reactions were observed in gabapentin capsules where GBP-Lactose conjugate impurity was formed. This impurity was characterized by Buchi et al. [87] by employing LC-MS technique.

The storage of formulation in extreme conditions may give rise to various product-related impurities, which was observed in the parenteral infusion of an amino acid supplement containing L-alanylL-glutamine by Simone et al. [63]. Authors were able to identify and quantify 21 impurities in the infusion after stress studies by employing liquid chromatography tandem mass spectrometry.

\section{Role of LC-MS in the profiling of degradation of drug substance}

Degradation is the inability of a particular drug substance in a specific container to remain within particular chemical, microbiological, therapeutical, physical, and toxicological specifications.

Development of degradation pathway can provide the information on possible impurities that may arise in the drug substance. In this regard, Thomas et al. [83] subjected eslicarbazepine drug to forced degradation studies and developed degradation pathway by separating the impurities by LC-UV followed by characterization using LC-MS/MS, NMR, and IR spectroscopy. Trandolapril degradation pathway was developed by Dendeni et al. [39], included the mechanism of degradation under chemical stress in both neutral and acidic conditions using UPLCESI-tandem mass spectrometry. In the same way, Mayuri et al. [91] developed the degradation pathway of Fenoxazoline by employing
HPLC-UV for separation and LC-MS/MS for the characterization of degradation products.

Role of LC-MS in the profiling of degradation of drug product Development of degradation pathway is important not only in drug substances but also in drug products. Nagdeep et al. [57] employed LC/ESI-MS/MS method for developing degradation pathway of dabigatran etexilate in both bulk drug and capsule formulation. Authors were able to identify 15 impurities among which two impurities were unknown. Degradation pathway was developed for the unknown impurities based on the information obtained from LC-MS, FTIR, Proton, and ${ }^{13} \mathrm{C}$ NMR spectroscopies.

Degradation of the drug product may also occur during the process of administration. Tiaziana et al. [75] identified degradation products for sodium risedronate granules for oral solution and effervescent tablets by carrying out oxidative degradation study. Authors employed LC-ESI-MS for determining the main degradation product.

Role of LC-MS in the profiling of genotoxic impurities

Genotoxic impurities cause the deleterious change in the genetic material regardless of the mechanism by which the change takes place.

Katerina et al. [59] and Szekely et al. [45] extensively worked on the analysis of potential genotoxic impurities in meropenem and glucocorticoids, respectively. Use of LC-MS/MS in the study helped in identifying genotoxic impurities in trace levels, reducing the cost per 
analysis, ultra-low limit of quantitation and obtaining high throughput results.

\section{CONCLUSION}

The above discussion, explains the importance of impurity profiling and various guidelines were enforced by various regulatory bodies to maintain the safety and quality of pharmaceutical products. The study also reveals that LC-MS is a better option for the structural elucidation of both known and unknown impurities. Most of the research work on impurity profiling includes the use of $\mathrm{C}-18$ column and mobile phases containing $0.1-1 \%$ of formic acid. Electron spray ionization under atmospheric pressure was preferred by the researchers for the impurity profiling mostly in positive ionization mode. Hybrid analyzers were preferred especially Q-Trap and Q-TOF. The present study may help the researchers in the selection of column, mobile phase, ionization technique, and analyzers for the LC-MS instrument and understand the ease with which the impurity profiling may be carried out using LC-MS.

\section{ACKNOWLEDGMENT}

The authors would like to thank the Principal, JSS College of Pharmacy, Jagadguru Sri Shivarathreeshwara University, Mysore, for providing the necessary facilities.

\section{REFERENCES}

1. Q3A(R2) Impurities in New drug Substances. ICH Guidelines; October 2006. Available from: http://www.ich.org/fileadmin/Public_Web_ Site/ICH_Products/Guidelines/Quality/Q3A_R2/Step4/Q3A__R2 Guideline.pdf

2. Sandor G. Identification and Determination of Impurities in Drugs. Amsterdam: Elsevier; 2000.

3. Saranjith S, Tarun H, Mallikarjun N, Archana S, Mahendra J, Ravi PS. A critical review on the use of modern sophisticated hyphenated tools in the characterization of impurities and degradation products. J Pharm Biomed Anal 2012;69:148-73.

4. Marie L, Valerie V, Claude V, Jean-Paul B, Nicolas L, Jean-Francois G. Structural elucidation of degradation products of a benzopyridooxathiazepine under stress conditions using electron spray orbitrap mass spectrometry- study of degradation kinetic. Eur J Pharm Sci 2012;45:559-69.

5. Mingkun F, Quing L, Elizabeth H, Jun W. Ultra high performance liquid chromatography coupled with high resolution quantitation mass spectrometry method development and validation for determining genotoxic 2,5- dichlorobenzoyl chloride in MLN-9708 drug substance. J Pharm Biomed Anal 2014;89:233-9.

6. Q3C(R6) Impurities Guideline for Residual Solvents. ICH Guidelines; 2016. Available from: http://www.ich.org/fileadmin/Public_Web_Site/ ICH_Products/Guidelines/Quality/Q3C/Q3C_R6_Step_4.pdf.

7. $\mathrm{Q} 3 \mathrm{~B}(\mathrm{R} 2)$ Impurities in New Drug Products. ICH Guidelines; 2006. Available from: http://www.ich.org/fileadmin/Public_Web_Site/ICH Products/Guidelines/Quality/Q3B_R2/Step4/Q3B_R2_Guideline.pdf.

8. Q3D Guideline for Elemental Impurities. ICH Guidelines; 2014. Available from: http://www.ich.org/fileadmin/Public_Web_Site/ICH Products/Guidelines/Quality/Q3D/Q3D Step 4.pdf.

9. M7(R1). Assessment and Control of DNA Reactive (mutagenic) Impurities in Pharmaceuticals to Limit Potential Carcinogenic Risk. ICH Guidelines; 2017. Available from: http://www.ich.org/fileadmin/ Public_Web_Site/ICH_Products/Guidelines/Multidisciplinary/M7/ M7 R1 Addendum Step 42017 0331.pdf.

10. Stephen TW, Susan IW, Jay AG, Casey DB. Production and characterization of impurities in Isofluranevapourizers. Anesth Analg 1985;64:634-9.

11. EMA/CHMP/CVMP/QWP/450653/2006. Assessment of the Quality of Medicinal Products Containing Existing/Known Active Substances. The European Agency for the Evaluation of Medicinal Product (EMEA); 2007. Available from: http://www.ema.europa.eu/docs/en_GB/ document library/Scientific guideline/2013/11/WC500155295.pdf.

12. $\mathrm{CPMP} / \mathrm{QW} \mathrm{W} / 1529 / 04$ Control of Impurities of Pharmaceutical Substances. The European Agency for the Evaluation of Medicinal Product (EMEA); 2004. Available from: http://www.ema.europa. eu/docs/en_GB/document_library/Scientific_guideline/2009/09/ WC500002924.pdf.

13. CPMP/SWP5199/02 and EMEA/CHMP/QWP/251344/2006 Guidelines on the Limit of Genotoxic Impurities. The European Agency for the Evaluation of Medicinal Product (EMEA); 2006. Available from: http://www.ema.europa.eu/docs/en_GB/document_library/Scientific guideline/2009/09/WC500003586.pdf.

14. EMEA/CHMP/SWP/4446/2000 Guideline on the Specification Limits for Residues of Metal Catalyst or Metal Reagent. The European Agency for the Evaluation of Medicinal product (EMEA); 2008. Available from: http://www.ema.europa.eu/docs/en_GB/document_library/ Scientific guideline/2009/09/WC500002903.pdf.

15. EMA/CHMP/CVMP/QWP/199250/2009 Guideline on Setting Specification for Related Impurities in Antibiotics. The European Agency for the Evaluation of Medicinal Product (EMEA); 2013. Available from: http://www.ema.europa.eu/docs/en_GB/document library/Scientific guideline/2012/07/WC500129997.pdf.

16. NDAs: Impurities in New Drug Substances. U.S Food and Drug Administration (USFDA); 2000. Available from: https://www.fda. gov/downloads/Drugs/GuidanceComplianceRegulatoryInformation/ Guidances/ucm070577.pdf.

17. ANDAs: Impurities in New Drug Substances. U.S Food and Drug Administration (USFDA); 2009. Available from: https://www.fda.gov/ downloads/Drugs/Guidances/UCM172002.pdf.

18. ANDAs: Impurities in New Drug Products. U.S Food and Drug Administration (USFDA); 2010. Available from: https://www.fda. gov/downloads/drugs/guidancecomplianceregulatoryinformation/ guidances/ucm072861.pdf.

19. Elemental Impurities in Drug Products. U.S Food and Drug Administration (USFDA); 2016. Available from: https://www.fda.gov/ downloads/Drugs/Guidances/UCM509432.pdf.

20. Geno-toxic and Carcinogenic Impurities in Drug Substances and Products: Recommended Approach. U.S Food and Drug Administration (USFDA); 2008. Available from: https://www.fda.gov/ohrms/ dockets/98fr/fda-2008-d-0629-gdl.pdf.

21. Impurities in Existing Drug Substances and Products. Health Canada; 2005. Available from: https://www.canada.ca/en/healthcanada/services/drugs-health-products/drug-products/applicationssubmissions/guidance-documents/chemical-entity-products-quality/ draft-guidance-industry-impurities-existing-drug-substances-products. $\mathrm{html}$.

22. Guidance 18: Impurities in Drug Substances and Drug Products. Therapeutic Goods Administration (TGA); 2013. Available from: http://www.tga.gov.au/sites/default/files/pm-argpm-guidance-18.pdf.

23. Lameck FS, Jaffrey SM. The determination of Chlorpromazine, related impurities and degradation product in pharmaceutical dosage forms. J Pharm Biomed Anal 1989;7:271-8.

24. Karljikovic KR, Novovic D, Marinkovic V, Agababa D. First order UV- derivative spectrometry in the analysis of omeprazole and pantoprazole sodium salt and corresponding impurities. J Pharm Biomed Anal 2003;32:1019-27.

25. Sylwester M, Roman S. Quantitative determination of captopril and prednisolone in tablets by FT-Raman Spectroscopy. J Pharm Biomed Anal 2006;40:1225-30

26. Jenny F, Fredrik OA, Sven PJ. NMR and Bayesian regularized neural network regression for impurity determination of 4- aminophenol. J Pharm Biomed Anal 2002;29:495-505.

27. Jette $T$, Steen H. Determination of impurities in tetracycline hydrochloride by non-aqueous capillary electrophoresis. J Chromatogr A 1996;737:291-300.

28. Hongyuan Y, Kyung HR. Rapid chiral separation and impurity determination of levofloxacin by ligand-exchange chromatography. Anal Chem Acta 2007;584:160-5.

29. James MM, Andrew CA, Donald AC. Determination of manufacturing impurities in Heroin by capillary gas chromatography with electron capture detection after derivatization with heptafluorobutyric anhydride. Anal Chem 1984;56:642-6.

30. Sidika E, Esra SA, Lale E, Samiye F. An HPLC method for the determination of atorvastatin and its impurities in bulk drug and tablets. J Pharm Biomed Anal 2003;33:1017-23.

31. Zhenyu W, Honggen Z, Oscar L, Brent D. Development of an orthogonal method for mometasonefuroate impurity analysis using supercritical fluid chromatography. J Chromatogr A 2011;1218:2311-9.

32. Krzek J, Hubicka U, Szczepanczyk J. High performance thin layer chromatography with densitometry for the determination of ciprofloxacin and impurities in drugs. J AOAC Int 2005;88:1530-6.

33. Swist M, Wilawmoski J, Zoba D, Kochana J, Parczewski A. Determination of synthesis route of 1-(3,4- methylenedioxyphenyl)-2propanone (MDP-2-P) based on impurity profiles of MDMA. Forensic Sci Int 2005;149:181-92. 
34. Novak TJ, Grinberg N, Hartman B, Marcinko S, Di Michele L, Mao B. LCMS using a hybrid quadrapole time of flight mass spectrometer for impurity identification during process chemical development of a novel integrase inhibitor. J Pharm Biomed Anal 2010;51:78-83.

35. Vaijanath GD, Pravin PK, Pradeep DG, Mukesh G, Bipin N, Chirag S, et al. Chracterization and quantitative determination of impurities in piperaquine phosphate by HPLC and LC/MS/MS. J Pharm Biomed Anal 2007;43:186-95.

36. Koki H, Hiroyuki Y, Koji Y, Hiroyuki N, Jun H. Novel sensitive determination method for genotoxic alkylating agent, 4-chlorobutanol, in active pharmaceutical ingredients by LC-ICP-MS employingiododerivatization. Anal Sci 2014;30:377-82

37. Maria CP, Carmen GR, Alejandro C, Antonio LC, Marria LM. Identification and quantitation of cis- ketoconazole impurity by capillary zone electrophoresis-mass spectrometry. J Chromatogr A 2006;1114:170-7.

38. LC-MS. A Brief History. LC-GC Solutions for Separation Scientists; 2013. Available from: http://www.chromatographyonline.com/lc-msbrief-history.

39. Dendeni M, Cimetiere N, Amrane A, Ben NH. Impurity profiling of trandolapril under stress testing: Structure elucidation of byproduct and development of degradation pathway. Int J Pharm 2012;438:61-70.

40. Ming JW, Jing X, Wen BZ, Yan W, Chang QH, Jos H, et al. Identification of the components of bitespiramycin of liquid chromatography-mass spectrometry. J Pharm Biomed Anal 2012;66:402-10.

41. Marvin CM. LC/MS: A practical User's Guide. Wiley Inter Science. Hoboken: A John Wiley \& Sons, Inc.; 2005.

42. Separation Condition 1 Fundamentals of a First Choice Mobile Phase. Shimadzu Excellence in Science. Available from: http://www. shimadzu.com/an/lcms/support/lib/lctalk/60/60lab.html

43. Ali RK, Mehradad F, Farshad S, Tahmineh B, Farzad K. Determination of impurities in illicit methamphetamine sample seized in Iran. Forensic Sci Int 2012;217:204-6.

44. Ming-Juan W, Ya-Ping L, Yan W, Jin L, Chang-Qin H, Jos H, et al. Characterization of the components of meleumycin by liquid chromatography with photo-diode array detection and electrospray ionization tandem mass spectrometry. J Pharm Biomed Anal 2013;84:69-76.

45. Szekely GY, Henriques B, Gil M, Ramos A, Alvarez C. Design of experiment as tool for LC-MS/MS method development for the trace analysis of potentially geno-toxic 4-dimethyl amino pyridine impurity in glucocorticoids. J Pharm Biomed Anal 2012;70:251-8.

46. Ira SL, Arthu LB, John FC, Reiko I, Joseph SB. Profiling of illicit fentanyl using UHPLC-MS/MS. Forensic Sci Int 2012;220:191-6.

47. Andras D, Gergo T, Jozser K, Szabolcs B. Structure elucidation of process related impurity of dapoxetine. J Pharm Biomed Anal 2014;96:272-7.

48. Ines G, Annabelle D, Theo H, Ivo BR, Melisande B, Christophe G, et al. Degradation pathways study of the natriuretic and $\beta$ adrenoceptoranatagonisttienoxolol using liquid chromatography- electronspray ionization multistage mass spectrometry. J Pharm Biomed Anal 2014;96:56-67.

49. Ya-Jie Z, Jiu-Ming H, Rui-Ping Z, Yu-Cheng W, Ju-Xian W, et al. An integrated approach for detection and characterization of trace impurities in levofloxacin using liquid chromatography-tendem mass spectrometry. Rapid Commun Mass spectrom. 2014;28:1164-74.

50. Cuimei L, Zhendong H, Yanping B. Classification of illicit heroin by UPLC-Q-TOF analysis of acidic and neutral manufacturing impurities. Forensic Sci Int 2015;257:196-202.

51. Patrik P, Kim H, Stephen B. Multiple heart-cutting two dimentional liquid chromatography mass spectrometry: Towards real time determination of related impurities of biopharmaceuticals in salt based separation methods. J Chromatogr A 2016;1468:95-101

52. Krishnam CR, Avadhesh KP, Gururaj S, Kaushik G, Arunima P, Sanath KG. et al. Isolation and characterization of novel degradation products of doxofylline using HPLC, FTIR, LCMS and NMR. J Pharm Biomed Anal 2017;140:1-10

53. Neeraj K, Subba RD, Prasad RG, Shailendra KD, Pramod K. Synthesis, isolation, identification and characterization of new process related impurity in isoproterenol hydrochloride by HPLC, LC-ESI/MS and NMR. J Pharm Anal 2017;7:394-400.

54. Jin L, Dousheng Z, Chang-Qin H. Characterization of impurities in cefpodoximeproxetil using LC-MSn. Acta Pharm Sin B 2014;4:322-32.

55. Peixi Z, Weifeng Y, Liya $\mathrm{H}$, Qiaoyuan $\mathrm{C}$, Lei L, Jiajia $\mathrm{H}$, et al. Characterization of a novel process related impurity in commercial bendazac lysine eye drops by LC-ESI-QTOF/MS/MS and NMR. J Pharm Biomed Anal 2015;107:437-43.
56. Moolchand K, Neha P, Shalu J, Prasad VB, Saranjith S. Characterization of forced degradation products oftorasemide through MS tools and explanation of unusual losses observed during mass fragmentation of drug and degradation products through density functional theory. J Pharm Biomed Anal 2017;145:209-18.

57. Nagdeep J, Kamaraj P, Arthanareeswari M. Gradient RP-HPLC method for the determination of potential impurities in dabigatranetexilate in bulk drug and capsule formulations. Arabian J Chem 2015. DOI: 10.1016/j.arabjc.2015.09.006

58. Custers D, Krakowska B, De Beer JO, Courselle P, Daszykowski M, Apers $\mathrm{S}$, et al. Chromatographic impurity fingerprinting of genuine and counterfeit Cialis ${ }^{\circledR}$ as a means to compare the discriminating ability of PDA and MS detection. Talanta 2016;146:540-8.

59. Katerina G, Yannis LC, Andelija M, Vicky S, Anastasia K, Efi D, et al. Chemometrically assisted development and validation of LCMS/MS method for the analysis of potential genotoxic impurities in meropenem active pharmaceutical ingredient. J Pharm Biomed Anal 2017;145:307-14.

60. Hanneke B, Arianvan A, Mattijs K, Jan D, Antione-Vender H, Peter S. Accurate quantitation of pentaerythritoltetranitrate and its degradation products using liquid chromatography-atmospheric pressure chemical ionization-mass spectrometry. J Chromatogra A 2014;1338:111-6.

61. Kaimin X, Shanshan S, Qun G, Wei S, Yuanjiang P, Jun W. Identification of a novel low-level impurity in fungicide pyraclostrobin by highperformance liquid chromatography/tandem mass spectrometry. J Pharm Biomed Anal 2017;138:272-6.

62. Simone S, Michael L, Wolfgang L. Comprehensive impurity profiling of nutritional infusion solutions by multidimensional off-line reversedphase liquid chromatography $\times$ hydrophilicinteraction chromatographyion trap mass-spectrometry and charged aerosol detection with universal calibration. J Chromatogr A 2012;1259:100-10.

63. Simone S, Michael L, Wolfgang L, Alexander L. Quantitative highperformance liquid chromatography-tandem mass spectrometry impurity profiling methods for the analysis of parenteral infusion solutions for amino acid supplementation containing 1-alanyl-1glutamine. J Chromatogr A 2012;1259:111-20.

64. Yao-Zuo Y, Mei Z, Xia-Lei F, Chang-Qin H, Shao-hong J, Ann VS, et al. Impurity profiling of etimicinsulfate by liquid chromatography ion-trap mass spectrometry. J Pharm Biomed Anal 2012;70:212-23.

65. Yao-Zuo Y, Mei Z, Xia-Lei F, Chang-Qin H, Shao-hong J, Ann VS, et al. Impurity profiling of micronomicinsulfate injection by liquid chromatography-ion trap mass spectrometry. J Pharm Biomed Anal 2013;75:94-104

66. Yao-Zuo Y, Mei Z, Xia-Lei F, Chang-Qin H, Shao-Hong J, Ann VS, et al. Analysis of impurities in vertilmicinsulfate by liquid chromatography ion-trap mass spectrometry. J Pharm Biomed Anal 2013;80:1-8.

67. Yuting L, Danyi Y, Zhiyu L, Taijun H, Min S. Isolation and characterization of related substances in alogliptin benzoate by LC-QTOF mass spectrometric techniques. J Pharm Biomed Anal 2016;128:253-63.

68. Ajay K, Subba RD, Shailendra KD, Pradeep K, Vishal S, Girish A, et al. Identification, synthesis and structural characterization of process related and degradation impurities of acrivastine and validation of HPLC method. J Pharm Biomed Anal 2017;133:15-26.

69. Abiramasundari A, Rahul PJ, Hitesh BJ, Jayesh AS, Dhaivath HP, Amith NP, et al. Stability-indicating assay method for determination of actarit, its process related impurities and degradation products: Insight into stability profile and degradation pathways. J Pharm Anal 2014;4:374-83.

70. Natasha S, Mark T, Tamsin K, Alison B, Shanlin F. Qualitative analysis of seized cocaine samples using desorption electrospray ionization- mass spectrometry (DESI-MS). Drug Test Anal 2014;7:393-400.

71. Elzbieta US, Anna R, Marek K, Joanna Z, Marein C, Lukasz K. Use of the hyphenated LC-MS/MS technique and NMR/IR spectroscopy for the identification of exemestane stress degradation products during the drug development. Eur J Pharm Sci 2017;109:389-401.

72. Bo C, Zhu-Qing G, Ying L, Yang-Min Z, Ying H, Jing-Pu Z et al. Embryo and Developmental Toxicity of Cefazolin Sodium Impurities in Zebrafish; 2017. Available from: https://www.frontiersin.org/ articles/10.3389/fphar.2017.00403/full.

73. Jian W, Xu Y, Chunmei W, Zhijian W. Application of a trap-free twodimensional liquid chromatography combined with ion trap/timeof-flight mass spectrometry for separation and characterization of impurities and isomers in cefpiramide. Anal Chim Acta 2017;992:42-54.

74. Yingping L, Bo J, Chen M, Tingting Z, Tong L. Identification of forced degradation products of tedizolid phosphate by liquid chromatography/ electrospray ionization tandem mass spectrometry. J Pharm Biomed 
Anal 2017;139:221-31.

75. Tiaziana B, Lorenza V, Silvia B, Paulo A, Rita G. A novel automated hydrophilic interaction liquid chromatography method using diodearray detector/electrospray ionization tandem mass spectrometry for analysis of sodium risedronate and related degradation products in pharmaceuticals. J Chromatogr A 2014;1365:131-9.

76. Chopra S, Pendela M, Hoogmartens J, Van Schepdael A, Adams E. Impurity profiling of capreomycin using dual liquid chromatography coupled to mass spectrometry. Talanta 2012;100:113-22.

77. Erwin A, Larissa VS, Frederick D, Ann VS, Jos H. Characterization of impurities in josamycin using dual liquid chromatography combined with mass spectrometry. J Pharm Biomed Anal 2013;73:66-76.

78. Volker N, Chris B, Knut R, Christian GH. Ultrahigh-performance liquid chromatography-ultraviolet absorbance detection-high-resolution-mass spectrometry combined with automated data processing for studying the kinetics of oxidative thermal degradation of thyroxine in the solid state. J Chromatogr A 2014;1371:196-203.

79. Xia Z, Jin L, Chen W, Danqing S, Changqin H. Identification of impurities in macrolides by liquid chromatography-mass spectrometric detection and prediction of retention times of impurities by constructing quantitative structure-retention relationship (QSRR). J Pharm Biomed Anal 2017;145:262-72.

80. Yu X, DanDan W, Lan T, Jian W. Separation and characterization of allergic polymerized impurities in cephalosporins by 2 D-HPSEC $\times$ LCIT-TOF MS. J Pharm Biomed Anal 2017;145:742-50.

81. Sushanth BJ, Kiran CK, Rakeshwar B, Bhonsale PN. Development of RP UPLC-TOF/MS, stability indicating method foromeprazole and its related substances by applying two level factorial design; and identification and synthesis of non-pharmacopoeial impurities. J Pharm Biomed Anal 2016;118:370-9.

82. Saji T, Subhash CJ, Dharam V, Ashutosh A, Raghavendra DR, Sridhar I, et al. Identification, characterization and quantification of a new impurity in deferasirox active pharmaceutical ingredient by LCESI-QT/MS/MS. J Pharm Biomed Anal 2012;63:112-9.
83. Thomas S, Bharti A, Maddhesia PK, Shandilya S, Agarwal A, Dharamvir, et al. Highly efficient, selective, sensitive and stability indicating RP-HPLC-UV method for the quantitative determination of potential impurities and characterization of four novel impurities in eslicarbazepine acetate active pharmaceutical ingredient by LC/ESI-IT/ MS/MS. J Pharm Biomed Anal 2012;61:165-75.

84. Saji T, Sanjeev S, Amber B, Saroj KP, Ashutosh A, Chandra SM. Identification, characterization and quantification of new impurities by LC-ESI/MS/MS and LC-UV methods in rivastigmine tartrate active pharmaceutical ingredient. J Pharm Biomed Anal 2012;57:39-51.

85. Xiangjun W, Hui Z, Jian-Bin Z, Chao H, Weixia L, Lushan Y, et al. Identification and characterization of four process-related impurities in retigabine. J Pharm Biomed Anal 2012;71:148-51.

86. Chopra S, Van Schepdael A, Hoogmartens J, Adams E. Characterization of impurities in tylosin using dual liquid chromatography combined with ion trap mass spectrometry. Talanta 2013;106:29-38.

87. Buchi RR, Kishore RM, Mukesh SJ, Brajesh S, Laki M. Identification, synthesis, isolation and characterization of formulation related impurity of Gabapentin. J Pharm Biomed Anal 2016;129:509-13.

88. Robert JD, Elaine S, Wenzhou L, Szilan F. Evidence for an imidazoline by-product from glycans using tandem mass spectrometry. J Chromatogr A 2017;1501:61-7.

89. Ruggenthaler M, Grass J, Schuh W, Huber CG, Reischl RJ. Impurity profiling of liothyronine sodium by means of reversed phase HPLC, high resolution mass spectrometry, on-line H/D exchange and UV/Vis absorption. J Pharm Biomed Anal 2017;143:147-58.

90. Musty S, Ravichandra BR. Determination and characterization of process related impurities in pazopanib hydrochloride drug substance. Int J Pharm Pharm Sci 2016;8:294-9.

91. Mayuri P, Krishna D, Krishnapriya M. Isocratic LC-UV, LC-MS and MS/MS studies on fenoxazoline and its degradation products. Int $\mathrm{J}$ Pharm Pharm Sci 2015;7:50-7. 